Bioscientia Medicina: Journal of Biomedicine \& Translational Research

Journal Homepage: www.bioscmed.com

\title{
Efficacy of Robusta Coffee Bean Extract (Coffea robusta) Against Bacterial Growth of Staphylococcus aureus
}

\section{Zulfan Muttaqin ${ }^{*}$, Lina Hadi ${ }^{1}$, Zara Maghfirah ${ }^{1}$}

${ }^{1}$ Dentist Education Program, Faculty of Dentistry, Universitas Prima Indonesia, Medan, Indonesia

\section{A R T I C L E I N F O \\ Keywords: \\ Antibacterial effect \\ Coffee extract \\ Staphylococcus aureus \\ Orthodontic \\ *Corresponding author: \\ Zulfan Muttaqin \\ E-mail address: mottakeane@gmail.com}

All authors have reviewed and approved the final version of the manuscript.

https://doi.org/10.37275/bsm.v6i4.493

\begin{abstract}
A B S T R A C T
Background. This research is a study that seeks to explore the potential of robusta coffee bean extract in inhibiting the growth of Staphylococcus aureus bacteria, where this bacterium is one of the bacteria that is often found in the oral cavity and often causes infections and dental and oral problems. Methods: This research is an experimental study in vitro. Robusta coffee extract was tested at levels of $25 \%, 12.5 \%, 6.25 \%$, and $3.125 \%$, where each test group was tested on 6 plates of Staphylococcus aureus bacteria. Data analysis was carried out with the help of SPSS 25 software. Results: There was a significant difference in the inhibitory power of Robusta coffee extract (Coffea robusta) at concentrations of $25 \%, 12.5 \%, 6.25 \%, 3.125 \%$ on the growth of Staphylococcus aureus bacteria. Significant differences in inhibition were found in group I and II ( $p=0.002$; mean diff $=-0.83)$, group I and III ( $p=0.000 ;$ mean diff $=-1.32)$, group I and IV $(p=0.000$; mean diff $=-2.12)$, group II with III $(\mathrm{p}=0.050$; mean diff $=-0.48)$, group II with IV $(p=0.000$; mean diff $=-1.28)$, and group III with IV $(p=0.002$; mean diff $=-0.80)$. Conclusion: Robusta coffee bean extract (Coffea robusta) has antibacterial activity against the growth of Staphylococcus aureus bacteria.
\end{abstract}

\section{Introduction}

Orthodontic treatment is a long-term treatment that generally takes about 2-3 years. The goals of the treatment, known as the Jackson's Triad, are functional efficiency, structural balance, and aesthetic harmony. Orthodontic treatment based on orthodontic appliances is classified as removable orthodontic and fixed orthodontic. The fixed device has a high maintenance capability, a very high probability of treatment success rate, and better treatment outcome specifications than removable devices. ${ }^{1-3}$ In addition to having a positive effect, fixed appliances also have a negative effect, namely, orthodontic appliances used can cause physicochemical changes in the oral cavity increasing cariogenic microorganisms. These bacteria can cause demineralization of tooth enamel. bacterial colonization Streptococcus mutans were higher in patients undergoing fixed orthodontic treatment than patients without orthodontic treatment. ${ }^{4}$

One of the antimicrobial agents as a gold standard that is commonly used in dentistry is chlorhexidine. Chlorhexidine is effective in controlling plaque accumulation as well as in the treatment of periodontal disease. A study stated that chlorhexidine with mouthwash was proven to be good for reducing the number of Streptococcus mutans and the use of chlorhexidine 0.2\% Streptococcus mutans by 30-50\%.5,6 
However, long-term use of chlorhexidine will cause side effects, namely yellow or brownish stains on the teeth, impaired taste, erosion of the oral mucosa, unilateral, bilateral parotid swelling, increased supragingival calculus formation, and changes in the balance of oral flora. Exploration of new therapeutic modalities is an urgency to minimize side effects. ${ }^{7}$

Coffee is one of the most important food commodities in the world and is also a popular drink. There are 124 species of coffee, but only 3 types are most often consumed and bred intensively, namely robusta coffee (Coffea robusta), arabica coffee (Coffea arabica), and liberica coffee (Coffea liberica). Indonesia is the fourth largest coffee producer in the world. Coffee is a superior export commodity because it has a high selling value, the demand for Indonesian coffee always increases every time. ${ }^{8}$ Robusta coffee varieties are dominated by African countries, India and Indonesia. In the Indonesian national market, robusta coffee is the most dominant commodity. Coffee is a plant that is believed to be ethnomedicine because it has many benefits. Robusta coffee contains several active compounds, namely chlorogenic acid, caffeine, trigonelline, and flavonoids. Chlorogenic acid is one of the ingredients with many pharmacological activities, namely antioxidant, antibacterial, antiviral hepatitis $B$, antihypertensive, antidiabetic, and hepatoprotector. ${ }^{9,10}$

Robusta coffee has a very good antibacterial effect, especially some bacteria $S$. aureus, E. coli, and $P$. aeruginosa. The study stated that robusta coffee had a significant antibacterial effect against Staphylococcus aureus and had an inhibitory concentration of at least $12.5 \%$. Another study stated that robusta coffee bean extract could reduce the growth of Escherichiacoli with a concentration of at least $10 \%$, the diameter of the inhibition zone was $22.5 \mathrm{~cm}$. stated that robusta coffee bean extract had antibacterial activity against Staphylococcus epidermidis and Salmonella typhi with concentrations of $3.125 \%, 6.25 \%, 12.5 \%$, and $25 \% .{ }^{11-}$ 13

This research is a study that seeks to explore the potential of robusta coffee bean extract in inhibiting the growth of Staphylococcus aureus bacteria, where this bacterium is one of the bacteria that is often found in the oral cavity and often causes infections and dental and oral problems.

\section{Methods}

This research is an in vitro experimental study. This study aims to determine the diameter of the inhibition zone of robusta coffee extract in the culture of Staphylococcus aureus. Robusta coffee extract was tested at levels of $25 \%, 12.5 \%, 6.25 \%$, and $3.125 \%$, where each test group was tested on 6 plates of Staphylococcus aureus bacteria. The process of making robusta coffee extract begins with the coffee beans being washed then cleaned and dried in an oven at a temperature of $60^{\circ} \mathrm{C}$. Furthermore, the dried coffee beans are then ground to obtain robusta coffee simplicia. Simplicia Robusta coffee as much as 200 grams dissolved with $70 \%$ ethanol as much as 2 liters for $3 \times 24$ hours. The macerate was then evaporated using a rotary evaporator to obtain a thick extract.

Use a sterile ose to take a colony of pure bacterial culture, grow it in an inclined agar medium, then use an incubator to incubate for $1 \times 24$ hours at $37^{\circ} \mathrm{C}$. Then prepare a petri dish and MHA (Mueller Hinton Agar) media. Until the density occurs, the petri dish will be poured $20 \mathrm{~mL}$ of MHA media. A sterile cotton swab soaked in bacterial suspension was then scratched evenly onto the solid surface of the MHA media. Incubate for 20 hours at $37^{\circ} \mathrm{C}$ using an incubator that has been prepared. After 20 hours, the authors will observe and check the diameter of the inhibition zone visible around the disc. The clear area of horizontal, vertical, and diagonal diameters can be measured using a caliper so that the authors can determine the diameter of the inhibition zone. The result is the average of the three expressed in millimeters.

Data analysis was carried out with the help of SPSS 25 software. Univariate data analysis was carried out to determine the mean inhibition zone diameter and standard deviation. Furthermore, an analysis was carried out to test the difference in the diameter of the inhibition zone between the test groups with one-way ANOVA followed by post hoc LSD, with a significance value of $\mathrm{p}<0.05$. 


\section{Results}

Differences in the inhibitory power of Robusta coffee bean extract concentrations of $25 \%, 12.5 \%, 6.25 \%$, $3.125 \%$ on the growth of Staphylococcus aureus were obtained $\mathrm{p}=0.000(\mathrm{p} \leq 0.05)$. From these results, it can be said that there is a significant difference in the inhibitory power of Robusta coffee extract (Coffea robusta) at concentrations of $25 \%, 12.5 \%, 6.25 \%$, $3.125 \%$ on the growth of Staphylococcus aureus (Table 1). Furthermore, the data were analyzed by post hoc statistical test LSD (Least Significant Difference) aimed at analyzing the differences in the inhibitory power of the two treatment groups to the growth of Staphylococcus aureus in the oral cavity. Based on the results of the study, it was found that there was a significant difference in inhibitory power between groups I and II ( $\mathrm{p}=0.002$; mean diff $=-0.83)$, group I and III $(p=0.000 ;$ mean diff $=-1.32)$, group I with IV $(p=0.000 ;$ mean diff $=-2.12)$, group II with III $(p=0.050$; mean diff $=-0.48)$, group II with IV $(p=0.000 ;$ mean diff $=-1.28)$, and group III with IV $(\mathrm{p}=0.002$; mean diff $=-$ 0.80) (Table 2).

Table 1. Inhibitory power of robusta coffee bean extract against Staphylococcus aureus bacteria

\begin{tabular}{|c|c|c|}
\hline Robusta coffee bean extract & $\begin{array}{c}\text { Inhibitory zone diameter } \\
\text { (mm) } \pm \text { SD }\end{array}$ & p-value \\
\hline $25 \%$ & $9.5 \pm 0.60$ & \multirow{2}{*}{$0.000^{*}$} \\
\hline $12.5 \%$ & $8.7 \pm 0.19$ & \\
\hline $6,25 \%$ & $8.2 \pm 0.22$ & \\
\hline $3.125 \%$ & $7.3 \pm 0.44$ & \\
\hline
\end{tabular}

* One way ANOVA test, $\mathrm{p}$ value $<0.05$

Table 2. Differences in inhibitory power between two treatment groups

\begin{tabular}{|c|c|c|c|}
\hline \multicolumn{2}{|c|}{ Robusta Coffee Extract Concentration } & Mean difference & p-value \\
\hline $3.125 \%$ & $6.25 \%$ & -0.83 & $0.002^{*}$ \\
\hline $3.125 \%$ & $12.5 \%$ & $-1,32$ & $0.000^{*}$ \\
\hline $3.125 \%$ & $25 \%$ & -2.12 & $0.000^{*}$ \\
\hline $6.25 \%$ & $12.5 \%$ & -0.48 & $0.050^{*}$ \\
\hline $6.25 \%$ & $25 \%$ & -1.28 & $0.000^{*}$ \\
\hline $12.5 \%$ & $25 \%$ & -0.80 & $0.002^{*}$ \\
\hline
\end{tabular}

*post hoc LSD, p $<0.05$

\section{Discussion}

The success of such a great treatment with better treatment results using a fixed orthodontic appliance is one of the tools in orthodontic treatment that is better than removable devices. However, on the other hand, the use of fixed orthodontic appliances can cause plaque accumulation. This can be caused by changes in the microbial flora in the mouth so that both aerobic and anaerobic oral bacteria increase during the first 3 months of use. One of the aerobic bacteria that causes dental plaque is Staphylococcus aureus. ${ }^{14-16}$ The potency of robusta coffee bean extract in inhibiting Staphylococcus aureus was determined from the large diameter of the inhibitor formed around the paper disc.
From the results of the study, it was obtained that the diameter of the inhibition was different from each treatment group. From these results, it was concluded that the higher the concentration of robusta coffee bean extract, the greater the diameter of inhibition against Staphylococcus aureus. The average inhibition diameter of Robusta coffee bean extract concentrations of $25 \%$, 12.5\%, 6.25\%, 3.125\% against Staphylococcus aureus was $9.5 \pm 0.60 ; 8.7 \pm 0.19 ; 8.2 \pm 0.22$; and $7.3 \pm 0.44$. From the results of the study, it can be seen that the smaller the concentration of Robusta coffee beans, the lower the inhibition diameter. The results of this study are in line with the study which stated that the concentration of robusta coffee bean extract at 3\%,1.5\%, 1.25\%, 1\%, 
$0.75 \%$, and $0.5 \%$ had different inhibitory effects. Concentrations of $0.5 \%$ and $0.75 \%$ of robusta bean extract had no inhibitory effect on Pophyromonas gingivalis, and 1\% concentration of Robusta coffee bean extract was the lowest concentration that could inhibit the development of Porphyromonas gingivalis. 17,18

Caffeine and trigonelline are some of the largest components of alkaloid compounds found in coffee beans which function as antibacterial. The study showed that trigonelline contained in Robusta coffee bean extract was positively correlated with a decrease in S. mutans biofilm formation through its bacteriostatic action. ${ }^{19}$ Another study showed that the content of trigonelline, caffeine and chlorogenic acid did not differ in their antimicrobial activity. Caffeic acid and trigonelline are known to have similar inhibitory effects on several microorganisms. Caffeine and chlorogenic acid are also known to have very strong antibacterial effects in inhibiting the growth of several other gram-positive bacteria. ${ }^{20,21}$

\section{Conclusion}

Robusta coffee bean extract (Coffea robusta) has antibacterial activity against the growth of Staphylococcus aureus bacteria.

\section{References}

1. Guo L, Feng Y, Guo HG, Liu BW, Zhang Y. Consequences of orthodontic treatment in malocclusion patients: clinical and microbial effects in adults and children. BMC Oral Health. 2016; 16(1): 1-7.

2. Alawiyah T. Complications and risks associated with orthodontic treatment. Widya Scientific Journal. 2017; 4(1): 256-61.

3. Marlisa W, Setyawan HS, Saraswati LD, Sakudarno MA. Differences in dental plaque scores, salivary $\mathrm{pH}$, and oral hygiene status in users and non-users of fixed orthodontic appliances. Journal of Public Health. 2017; 5(3): 113-9.

4. Fajriani AJN. Reduction of salivary Streptococcus mutans colonies in children after rinsing with $2.5 \%$ green tea solution. $J$ Dentistry Indonesia, 2014; 21(3): 79-84.

5. Leonarto, MN, Habar EH. The impact of mouthrinsing using chlorhexidine gluconate $0.2 \%$ to the amount of plaque-causing bacteria colonies in fixed orthodontic users. J Dentomaxillofac Sci. $2017 ; 2(2)$ : 91-4.

6. Mummolo S, Tieri M, Nota A, Caruso S, Darvizeh A, et al. Salivary concentrations of Streptococcus mutans and Lactobacilli during an orthodontic treatment. An observational study comparing fixed and removable orthodontic appliances. Clin Exp Dent Res. 2020; 6(2): 181-7.

7. Selvaraj A, Felicita S, Girija S. Prevalence of oral microbial flora during orthodontic space closure: a pilot study. J Clin Diagnostics Res. 2020; 4(10): ZC16-20.

8. Dianastri NT, Astuti P, Prasetya RC. Inhibition of robusta coffee bean extract (Coffea Canephora) against Porphyromonas gingivalis (in vitro). Stomatognatic: JKG UNEJ. 2021; 18(2): 69-73.

9. Siebert M, Berger RG, Nieter A. Enzymatic mitigation of 5-O-chlorogenic acid for an improved digestibility of coffee. Food Chem. 2018; 258: 124-8.

10. Singh P, Kaur M, Singh I. Efficacy of chlorhexidine vs herbal mouthwash in college students: a comparative study. Int $\mathrm{J}$ Med Health Research. 2017; 3(5): 78-81.

11. Azzahra F, Hayati M. Activity test of gotu kola leaf extract (Centella asiatica (L). urb) on the growth of Streptococcus mutans. JB Dent. 2018; 5(1): 9-19.

12. Bauer D, Abreu J, Santos J, Freitas-silva O, Teodoro A. Effect of roasting levels and drying process of Coffea canephora on the quality of bioactive compounds and cytotoxicity. Int $\mathrm{J}$ Mol Sci. 2018; 19(3407): 1-19.

13. Lubis MRF, Lindawati Y. Effects of Robusta coffee bean extract (Coffea canephora) on salivary $\mathrm{pH}$ and the growth of Staphylococcus 
aureus (ATCC $\AA 29213^{\mathrm{TM}}$ ) bacteria (in vitro). J Scientific Pannmed. 2018; 12(3): 309-12.

14. Kaligis FR, Fatimawali, Lolo WA. Identification of bacteria in patient's dental plaque at Bahu Health Center and test for resistance to chloramphenicol and lincosamide antibiotics (Clindamycin). Pharmacon J Scientific Pharmacy. 2017; 6(3): 223-32.

15. Maheasy FL, Atun S. Antibacterial activity test of ethanol extract of TemuKEY (Boesenbergia pandurata) against Streptococcus mutans bacteria. J Scientific Research. 2017; 2(1): 5966.

16. Phulari BS. Orthodontics principles and practice. 2ndEd. New Delhi: Jaypee Brothers Medical Publishers. 2017; 1-5: 319-20.

17. Ranasatri AA, Mahmudah N, Aisyah R, Sintowati R. Antibacterial activity 70\% ethanolic extract of robusta coffee bean (Coffea canephora) Against Staphylococcus epidermidis and Salmonella typhi. biomedicine. 2020; 13(2): 101-10.

18. Shukla C, Murya RK, Singh V, Tijare M. Evaluation of changes in Streptococcus mutans colonies in microflora of the Indian population with fixed orthodontics appliances. Dent Research J. 2016; 13(4): 309-14.

19. Tanauma HA, Citraningtyas G, Lolo WA. Antibacterial activity of Robusta coffee bean extract (Coffea canephora) against Escherichia coli bacteria. Pharmacon J Scientific Pharmacy. 2016; 5(4): 243-51.

20. Dastjerdi EV, Abdolazimi Z, Ghazanafrian M, Amdjadi P, Kamalinejad M, et al. Effect of Punica granatum L. flower water extract on five common oral bacteria and bacterial biofilm formation on orthodontic wire. Iranian $\mathrm{J}$ Pub Health. 2014; 43(12): 1688-94.

21. Yuwono HS. The new paradigm of wound management using coffee powder. J Surg. 2014; 2(2): 25-9. 